OSCOLA, a UK standard for legal citation

By Sandra Meredith

Law Faculty, St Cross Road, Oxford University, OX1 3UL (sandra.meredith@law.ox.ac.uk)

Abstract:

OSCOLA, the Oxford Standard for the Citation Of Legal Authorities, was first devised in 2000. The fourth edition, published in November 2010, for the first time includes guidelines for citing Scottish, Irish and Welsh cases and legislation, historical legal sources and new media such as blogs. It also provides more extensive general advice about using quotations, managing and cross-referencing footnotes, and organising bibliographies and tables of cases and legislation. OSCOLA is supported by styles for bibliographic software such as Endnote, and is fast becoming the UK national standard for legal citation.

Biography:

Sandra Meredith is Departmental Lecturer in Legal Research Skills for the Law Faculty at Oxford University and co-editor of OSCOLA.

Word count: 2403 (excluding the preliminary material above) 


\section{A brief history}

The essence of OSCOLA, the Oxford Standard for the Citation of Legal Authorities, is perhaps best captured in the introduction:

There are two golden rules for the citation of legal authorities. One is consistency. The other is consideration for the reader. Legal writing is more persuasive when the author refers to legal materials in a clear, consistent and familiar way. When it is easy to identify and to find the author's sources, it becomes easier for the reader to follow the argument. The Oxford Standard for Citation of Legal Authorities (OSCOLA) is designed to help the author to achieve consistency and to make life easier for the reader.

OSCOLA was first devised in 2000 by the then Regius Professor of Civil Law in the Oxford Law Faculty, Peter Birks, with the aim of reducing the "woeful waste of scholarly time caused by the absence of a national standard for citation". " The first version was developed in consultation with Oxford University Press, Hart Publishing, the Oxford University Law Faculty and the editors of the Oxford University Commonwealth Law Journal (OUCLJ), and revised in 2002. In 2004, after Professor Birks' untimely demise, Professor Timothy Endicott and I produced a new edition of OSCOLA. We revised it lightly in 2006. By this time, it was being adopted by growing numbers of university law schools and publishers.

In 2007 Donal Nolan, Fellow and Tutor in Law at Worcester College and CUF Lecturer in the Oxford Law Faculty, became co-editor in place of Professor Endicott, who had become Dean of the Faculty. In recognition of the wider usage of OSCOLA, an editorial advisory board was established in 2009 in advance of the fourth edition revision. The board includes representatives from Hart, OUP and Butterworths publishers, the UKCLE, the OUCLJ, university law libraries, and the Oxford Law Faculty. Librarians made particularly helpful contributions to the revision, especially Dr Peter Clinch of Cardiff, now retired. Gareth Ryan from the University of Strathclyde contributed a great deal towards the section on citing Scottish legal sources. The fourth edition was published in November 2010 as a free downloadable pdf booklet with a separate two-page quick reference guide on www.law.ox.ac.uk/oscola.

This edition includes advice for citing Scottish, Irish and Welsh cases and legislation for the first time. It also provides more detailed advice for citing cases before 1865, books published before 1800, and books of authority and institutional works. More general citation advice is included on matters such as how to organise a bibliography and tables of cases and legislation, how to present quotations, and how to order sources and deal with subsequent citations and cross references in footnotes. The section on citing international law sources in previous editions has not been updated for the fourth edition, although it remains available as a separate document on the OSCOLA webpages.

\section{What do OSCOLA citations look like?}

OSCOLA is a footnoting style. It provides rules and examples for the main UK primary legal sources and for many secondary sources. Generic guidelines for citation of secondary sources are also provided, to help users work out how to reference sources for which OSCOLA provides no examples. The guidelines are developed from common practice in UK legal citation, but with a minimum of punctuation.

\footnotetext{
${ }^{1}$ Email from Peter Birks to Sandra Fredman, Law Faculty, Oxford University (16 March 2001).
} 
Legal citation can be complex for various reasons. Case citation, for example, is complicated owing to to several factors. One is neutral citations for judgments, which the House of Lords, Privy Council, Court of Appeal and Administrative Court began issuing in 2001, a practice that was extended to other courts and tribunals in subsequent years. Neutral citations identify the year of the judgment, the court and the judgment number, with judgments being numbered consecutively throughout the year. If a judgment is issued with a neutral citation, it must be cited, after the party names, and before a citation for the 'best report'.

This requirement for citation of the 'best report' is another complexity. It means the writer or advocate must provide a citation from the Law Reports (Appeal Cases, Queen's Bench, Chancery etc), or if that is not available from the Weekly Law Reports or the All England Law Reports, as well as the neutral citation. Although the writer may first read a judgment online, when it only has a neutral citation, or in a specialist report, the WLR or All ER, he or she should check to see if it has been published in a Law Reports series before finalising their work. These requirements have been stated by the courts in several Practice Directions and, most recently, in a Court of Appeal judgment. ${ }^{2}$

A case citation with a neutral citation and a citation from the Appeal Cases looks like this:

Corr v IBC Vehicles Ltd [2008] UKHL 13, [2008] 1 AC 884.

If the writer is referring to specific paragraphs in the judgment, those paragraphs are indicated within square brackets at the end of the citation:

Bunt v Tilley [2006] EWHC 407 (QB), [2006] 3 All ER 336 [1]-[37].

Cases without neutral citations, which means all cases in England and Wales before 2001, require citation of the 'best report' followed by the court abbreviation in brackets:

Page v Smith [1996] AC 155 (HL).

Numbering of paragraphs began concomitantly with neutral citations. With older judgments that do not have numbered paragraphs, if the writer is referring to a specific part of the judgment, page numbers are cited. They follow the court:

$$
R v \text { Leeds County Court, exp Morris [1990] QB } 523 \text { (QB) 530-31. }
$$

Cases before 1865 are cited a little differently, as are cases from the European Court of Justice, which have a case number that precedes the party names. Yet another complexity in case citation is that if the name of a case is mentioned in the text, it is not necessary to repeat the party names in the footnote. Subsequent citations of cases are also treated in specific ways. Experienced legal writers and librarians are familiar with these conventions and probably find them straightforward, but novices can find case citation challenging. About a fifth of OSCOLA is devoted to discussion of how to cite cases, along with clear rules and examples.

Another practice familiar to lawyers but not to novices in the field is citation of journal articles. Legal journals with consecutive volume numbers are cited by author, title, and then the year of publication in brackets, followed by the volume number, abbreviation and first page. There are no italics. For example,

\footnotetext{
2 [1995] 1 WLR 1096; [1998] 1 WLR 825; [2001] 1 WLR 194; [2002] 1 WLR 346; TW v A City Council [2011] EWCA Civ 17 [6]-[7].
} 
Paul Rollins, 'Managing Copyright Information' (2010) 10 LIM 183.

When citing a journal that doesn't have consecutive volume numbers, such as Public Law, the year of publication is placed within square brackets:

John Ip, ‘The Rise and Spread of the Special Advocate' [2008] PL 717, 726.

If citing a particular page, the page number follows at the end of the citation after a comma. The above example indicates that a particular quote, paraphrase or idea can be found on page 726 of John Ip's article. In my experience, this way of citing journal articles is peculiar to law.

In contrast to journal citation, book citation is quite simple in OSCOLA. The author is provided first, followed by the title in italics, both of which are common practices in many citation styles. The publication details follow within brackets. The minimum publication details required are the publisher and year of publication. City of publication is no longer required. Any additional information, such as a series title or translator's name or details about the first publication date of older texts, is provided within the brackets, before the city and year. Any page number references are at the end of the citation, outside the brackets, without a p. or page.

Thomas Hobbes, Leviathan (first published 1651, Penguin 1985) 268.

Legal citation faces the same kinds of problems as other citation styles when it comes to citing new media. OSCOLA gives advice for citing websites and blogs, however postings on discussion forums, social media such as Facebook and Twitter, and online newspaper comment sections are not specifically covered. While these kinds of sources should be cited with caution -- they are often ephemeral and generally lack the authority of peer-reviewed books and journal articles -- they will become increasingly common sources in the future, and citation guidelines will need to be developed for them. Another example of new media causing citation problems is Kindle books, which apparently don't always have page numbers.

Yet another way in which legal citation can be complex is that different journals and publishers do it in different ways. Secondary legal sources such as Hansard, Parliamentary Reports and Command Papers, books of authority and looseleaf services are cited in various ways in different publications. The same is true of secondary sources that are not specifically legal, from books and journals to conference papers, newspaper articles and websites. This kind of variation has long been costly for both writers and publishers. Cutting this cost was one of Professor Birks' ambitions; he spoke of his drive to establish OSCOLA as being "rooted in the anger which I have felt on my own account and on account of others when told to spend whole weeks turning one perfectly good set of footnotes into another style". ${ }^{3}$ The adoption of a national standard for citing both primary and secondary legal sources should save time not only for legal writers, but also for publishers of print and online sources, particularly given the demand for hyperlinked sources.

\section{Who uses OSCOLA?}

The fourth edition of OSCOLA was published in November 2010. In the three-month period November 2010 to January 2011, there were 37,467 unique views on the OSCOLA home page. A quarter of those looking at the page clicked through to the OSCOLA Endnote style page. We assume that many of the others downloaded OSCOLA or the quick reference guide. Some of these hits come

\footnotetext{
${ }^{3}$ Peter Birks, Notes on a Memorandum for the Graduate Studies Committee, Law Faculty, Oxford University, April 2001.
} 
via the many law schools in British universities that advise their students to use OSCOLA. A Google search for OSCOLA finds at least $50 \mathrm{UK}$ universities with links from their publicly accessible webpages to the OSCOLA home page. A similar search in the summer of 2007 found links to OSCOLA from 31 UK universities, so, by that measure at least, there has been an increase in OSCOLA usage. Librarians, and occasionally lecturers, in at least 20 of these universities have developed their own, shorter, OSCOLA-based guides for their law students. Many law school websites also point to Cardiff University's 'Citing the Law' online tutorial, ${ }^{4}$ which shows students how to cite legal authorities using OSCOLA. Portsmouth University also has a sophisticated online tutorial for using OSCOLA ${ }^{5}$ and there are probably more short OSCOLA guides and tutorials beyond password boundaries. The OUP Dictionary of Law has included a section on using OSCOLA since 2007, and the most recent edition of Palgrave's Cite Them Right includes a section on using OSCOLA. ${ }^{6}$ Overseas universities in Africa, Asia, Europe, and the US also link to OSCOLA.

Among legal publishers, OSCOLA is recommended by at least OUP, Hart and Elgar. Most OUP and Hart journals use it, including the Oxford Journal of Legal Studies and the Oxford University Commonwealth Law Journal. It is also the guide for journals published by Elgar, Taylor \& Francis, de Gruyter, Brill, Merkourios, Emerald, and the International and Comparative Law Quarterly. Most university law journals in the UK use OSCOLA, as do some in the rest of Europe.

\section{OSCOLA and reference software}

An OSCOLA style for Endnote has been available on the OSCOLA webpages since 2004. The style has been continually updated. It comes in two versions: one for personal computers and one for using on networks and shared computers. As legal scholarship is so broad, many writers benefit from adjusting or adding to the OSCOLA Endnote style, which is only really possible on personal computers. The Endnote style for personal computers - OSCOLA 2 - comes with a modified 'RefTypeTable'. The information in the Ref Type Table is effectively the headings in the various fields in the Endnote References. For example, for the Journal Reference Type, there is a heading called 'Add year here if there is a volume number', to allow for both round bracket and square bracket journal citations (see above). The current version of OSCOLA 2 is OSCOLA_2_4th_edn.ens. The other style, simply called OSCOLA, uses the default reference types in Endnote. Documents created using this style require adjustment of journal article brackets after the citations and bibliography have been converted to plain text (de-linked from Endnote). The current version of the OSCOLA style is OSCOLA_4th_edn.ens. There is also support documentation for the OSCOLA Endnote styles. OSCOLA is sufficiently widely used in Endnote that Adept Scientific distributed its own press release when the fourth edition of OSCOLA became available.

In December 2008, a beta version of the OSCOLA style was created for RefWorks. I have had no feedback about this style. It has not yet been updated for the fourth edition of OSCOLA. Citavi, a Swiss bibliographic software, also has a style for OSCOLA. Very recently at the Oxford University Law Faculty we have established a working group to develop an OSCOLA style for Zotero, the free browser-based citation software. This software uses Citation Style Language (CSL), which is xml. Anyone OSCOLA users experienced with CSL and interested in helping with this project are more than welcome to contact me.

\footnotetext{
${ }^{4}$ Cathy Jackson and Ian Bradley, 'Citing the Law' $<$ https://ilrb.cardiff.ac.uk/citingreferences/oscola/tutorial/index.html> accessed 15 March 2001.

5 'Referencing@ Portsmouth'< http://referencing.port.ac.uk/oscola/index.html> accessed 15 March 2001.

${ }^{6}$ Richard Pears and Graham Sheilds, Cite Them Right: The Essential Referencing Guide ( $8^{\text {th }}$ edn, Palgrave Macmillan 2010).
} 


\section{Conclusion}

Feedback on OSCOLA is always welcome (write to oscola@law.ox.ac.uk). OSCOLA is revised every two to three years, although the fourth edition took a little longer than that. As OSCOLA will be published in hard copy in the near future, timely feedback on the fourth edition is particularly sought. Although a hard copy will be available for those who prefer to work with a book, OSCOLA pdfs will remain freely available for download. We hope that it will continue to become more broadly used by publishers and in the legal professions as well as in universities. 